\title{
2 \\ O ACESSO À JUSTIÇA COMO DIREITO FUNDAMENTAL E SUA EFETIVAÇÃO JURISDICIONAL
}

The access to justice as a fundamental right and its effective judicial

\section{Juvêncio Borges Silva}

Mestre pela UNICAMP, doutor pela UNESP, pós-doutor em direito pela Faculdade de Direito da Universidade de Coimbra-PT, professor do programa de pós-graduação stricto sensu em Direito da Universidade de Ribeirão Preto UNAERP. E-mail: juvborges@netsite.com.br

\section{RESUMO}

O acesso à justiça tem sido uma temática recorrente nos estudos jurídico-sociais. Anecessidade de uma ampliação do acesso à justiça precisa ser considerada em seu contexto histórico-social, contemplando em sua análise os elementos ideológicos que o envolvem, bem como a estrutura jurídica e os modelos seguidos pelos operadores do direito, norteando-se acima de tudo pela compreensão de que o acesso à justiça é um direito fundamental inserido na Constituição Federal Brasileira. Constata-se que, com o advento dos direitos sociais e coletivos, ocorreu uma mudança de paradigma no direito, até então individualista, exigindo novos diplomas jurídicos e novos procedimentos judiciais e extrajudiciais para fazer frente aos novos direitos e ao aumento da conflituosidade social na sociedade complexa. É neste quadro histórico, social, ideológico e jurídico que o acesso à justiça deve ser considerado, analisado e compreendido como um direito fundamental, fazendo-se necessário, para sua plena realização a sua efetivação jurisdicional.

Palavras-Chave: Acesso à justiça. Direito fundamental. Efetivação JURISDICIONAL. 


\begin{abstract}
Access to justice has been a recurrent theme in social-legal studies. The need for increased access to justice must be seen in its historical and social context, contemplating in his analysis ideological elements that surround it, as well as the legal and models followed by law operators, guiding themselves above all by understanding that access to justice is a fundamental right inserted in the Brazilian Federal Constitution. It appears that, with the advent of social rights and collective, a paradigm shift occurred in the right hitherto individualistic, demanding new legislation and new legal and extrajudicial procedures to cope with new rights and to increased social conflict in society complex. It is in this historical context, social, ideological and legal access to justice should be considered, analyzed and understood as a fundamental right, making it necessary for its completion its realization court.
\end{abstract}

Keywords: Access to Justice. Fundamental Rights. Judicial EXECUtion.

SumÁRIo: Introdução. 1. Acesso à justiça: aspectos histórico-sociais. 2. Acesso à justiça e documentos internacionais. 3. Acesso à justiça como direito fundamental na Constituição Brasileira. 4. Obstáculos ao acesso efetivo à justiça. 4.1. Obstáculo econômico. 4.2 Obstáculo temporal e estrutural. 4.3. Obstáculo de natureza pessoal. 5. Caminhos de efetivação do acesso à justiça. 5.1. A tutela coletiva como instrumento de efetivação do acesso à justiça. 5.2. Os juizados especiais como meios céleres de acesso à justiça. 5.3. A Assistência Judiciária como instrumento de efetivação de acesso à justiça às pessoas declaradamente pobres. 5.4. ADefensoria Pública como instrumento de efetivação de acesso à justiça aos necessitados. 5.5. As faculdades de direito e a prestação judiciária: seu papel na efetivação do acesso à justiça. 5.6. A conciliação como meio de resolução de conflitos e sua importância para a efetivação do acesso à justiça. Conclusão. Referências.

\title{
INTRODUÇÃo
}

$\mathrm{O}$ acesso à justiça constitui tema da maior relevância no direito, pois como observam Cappelletti e Garth (1999, p. 12), “o acesso à justiça pode, portanto, ser encarado como o requisito fundamental - o mais básico dos direitos humanos - de um sistema jurídico moderno e igualitário que pretenda garantir, e não apenas proclamar os direitos de todos". 
É assim que, no final do século XX se fez emergir um novo conceito de direito ao acesso à justiça, consistente em garantir ao cidadão, não apenas o direito de petição ao Poder Judiciário, mas também o direito fundamental à efetiva prestação da justiça.

A expressão "acesso à justiça", não obstante as dificuldades no que tange à sua definição, assim foi considerada por Capelleti e Garth $(1988$, p. 8):

A expressão "acesso à Justiça" é reconhecidamente de difícil definição, mas serve para determinar duas finalidades básicas do sistema jurídico - o sistema pelo qual as pessoas podem reivindicar seus direitos e/ou resolver seus litígios sob os auspícios do Estado. Primeiro, o sistema deve ser igualmente acessível a todos; segundo, ele deve produzir resultados que sejam individual e socialmente justos.

Na primeira acepção, o acesso à Justiça implica em que o sistema judiciário deve ser acessível a todas as pessoas, indistintamente, independentemente de raça, sexo, condição social etc. Na segunda acepção, o sistema judiciário precisa também ser efetivo, ou seja, precisa distribuir justiça no âmbito individual e social. Nesta segunda perspectiva, o sistema judiciário deve ser um instrumento para mitigar as injustiças sociais, contemplando os aspectos de natureza social em suas decisões.

Entretanto, esta concepção, que parece totalmente aceitável atualmente, no seu sentido mais abrangente, não o foi de forma ampla no passado, e necessita de maior efetividade no presente.

\section{ACESSO À JUSTIÇA: ASPECTOS HISTÓRICO-SOCIAIS}

É preciso que consideremos que os avanços político-sociais pós Revolução Francesa foram lentos. Num primeiro momento as mudanças de natureza política beneficiaram mais diretamente aqueles que detinham o poder econômico. Ainda que a revolução tenha posto fim ao poder absolutista, e tenha consagrado o Estado constitucional, com limites definidos para a atuação do Estado, bem como tenha afirmado os direitos individuais, de início, alguns eram considerados mais cidadãos que outros, haja vista a instituição do voto censitário, que estabelecia que somente os cidadãos que tivessem uma determinada renda poderiam votar e ser votados.

Esta categorização dos cidadãos acabou por restringir o acesso à Justiça para os menos afortunados e, ainda mais, para os que nada tinham. Ocorreu, de início, uma elitização no que tange ao acesso à Justiça.

Nos países que foram amplamente afetados pela instituição da escravidão, este fosso entre os cidadãos se alargou ainda mais. Afinal, tinha-se a figura 
do homem livre e de posses (cidadão), do homem livre e pobre (sub-cidadão) e do escravo, que pertencia à ordem dos semoventes. Tal situação é exposta amplamente por Joaquim Nabuco em "O Abolicionismo" (1988).

Afirma Cardoso (1977, p. 247), que “a escravidão acabou por tornar o trabalho vil, e despertar no coração dos homens livres a vergonha pelo trabalho braçal", o que teria levado muitos negros no sul do país, após a abolição, a rejeitar o trabalho braçal como forma de afirmação de sua liberdade.

Maria Sylvia de Carvalho Franco, relatando a condição dos homens livres e pobres na ordem escravocrata e o seu acesso à justiça aponta um caso concreto no qual colonos que figuraram como denunciantes de um crime de homicídio no Estado de São Paulo, na cidade de Guaratinguetá foram desqualificados pelo advogado do réu em razão de sua condição social:

Essa completa ausência do reconhecimento social do homem pobre vai mesmo à afirmação de sua insuficiência para o exercício dos mais elementares direitos do cidadão, como o recurso à Justiça. Escreve um advogado: "o órgão da justiça é réu confesso de pouca reflexão e circunspecção no exercício de seu nobre e delicadíssimo dever de denunciar. Dos autos consta que foram colonos subservientes que denunciaram o fato. Pois bem, sua senhoria assim procedendo abriu um precedente horroroso, porque nem o meritíssimo julgador, nem o abaixoassinado, estão livres de amanhã serem intimados para defenderem-se de uma denúncia de homicídio dada por um caboclo qualquer, agregado ou colono de um desafeto e que se diz paciente do delito. O órgão da justiça, pressuroso, acolheu a denúncia de um caboclo, sem responsabilidade moral, menos ainda social, um trabalhador boçal de enxada, que não tem nome, nem posição, e nem reputação a zelar... E hoje o órgão da justiça, ao ver que as próprias testemunhas da acusação defendem o acusado há de trazer a sua consciência bem acabrunhada e exprobrar-se amargamente a facilidade com que prestou fé a caboclos", (FRANCO, 1988, p. 104).

Bem concluiu a professora Maria Sylvia que estes homens livres eram desqualificados socialmente e moralmente. E desqualificados por quê? Porque não tinham propriedades, "nome", "posição", "reputação".

Assim, a expressão "acesso à justiça” deve ser compreendida em seu contexto histórico e social, envolta por elementos ideológicos de dominação, de interesses de classes, de preservação de privilégios.

$\mathrm{O}$ conceito de acesso à justiça tem experimentado ao longo do tempo, mudanças. Se antes (sec. XVIII e XIX) o acesso à justiça era um reflexo da filosofia individualista dos direitos prevalecentes à época (CAPPELLETTI e 
GARTH, 1988, pp. 9 -13), configurando-se em um direito de natureza meramente formal, que consistia no direito do indivíduo agravado de propor ou contestar uma ação, hoje considera-se a existência de um acesso efetivo à justiça.

Aconcepção presente nos séculos XVIII e XIX era o reflexo do pensamento liberal então predominante no âmbito político-jurídico. A compreensão que se tinha à época era de que não havia a necessidade de uma ação por parte do Estado com vistas à proteção dos direitos individuais, que eram tidos como naturais. Assim, o que se esperava do Estado era tão somente uma ação garantista de sua não-violação. O Estado quedava-se passivo ante os problemas conflituosos de natureza material entre as partes.

No contexto do Estado liberal o acesso à justiça acabava relegado àqueles que dispunham de condições pecuniárias para arcar com as custas processuais, ficando os pobres alijados do acsso à justiça. $\mathrm{O}$ acesso à justiça, afirmam Cappelletti e Garth, era tão somente formal e, de igual forma, a igualdade, o que passa a mudar em razão das próprias transformações experimentadas pela sociedade:

À medida que as sociedades do laissez-faire cresceram em tamanho e complexidade, o conceito de direitos humanos começou a sofrer uma transformação radical. A partir do momento em que as ações e relacionamentos assumiram, cada vez mais, caráter mais coletivo que individual, as sociedades modernas necessariamente deixaram para trás a visão individualista dos direitos, refletida nas "declarações de direitos", típicos dos séculos XVIII e XIX. O movimento fez-se no sentido de reconhecer os "direitos e deveres sociais" dos governos, comunidades, associações e indivíduos. Esses novos direitos humanos, exemplificados pelo preâmbulo da Constituição Francesa de 1946, são, antes de tudo, os necessários para tornar efetivos, quer dizer, realmente acessíveis a todos, os direitos antes proclamados. Entre esses direitos garantidos nas modernas constituições estão os direitos ao trabalho, à saúde, à segurança material e à educação. Tornou-se lugar comum observar que a atuação positiva do Estado é necessária para assegurar o gozo de todos esses direitos sociais básicos. (CAPPELLETTI e GARTH, 1988, pp. 10-11).

É no contexto deste quadro social que Capellettti e Garth reconhecem que o direito de acesso à justiça ganhou particular atenção, uma vez que "as reformas do welfare state têm procurado armar os indivíduos de novos direitos substantivos em sua qualidade de consumidores, locatários, empregados e, mesmo, cidadãos" (1988, p. 11).

$\mathrm{O}$ direito de acesso à justiça passa a ser considerado como essencial, uma vez que de pouca valia seria o direito material sem as condições de o sujeito 
de direitos torná-los efetivos. Para tanto, faz-se necessário que os juristas reconheçam que as técnicas processuais servem a funções sociais.

\section{ACESSo À JUSTiÇA E DOCUMEnTOS INTERnACiOnAIS}

O primeiro documento de alcance internacional a reconhecer o direito a efetiva e pronta prestação jurisdicional foi a Convenção Europeia de Direitos Humanos (COMPARATO, 2005, pp. 222-237) adotada pelo Conselho da Europa em 1950 e que entrou em vigor em 1953. O nome oficial da Convenção é Convenção para a proteção dos Direitos do Homem e das liberdades fundamentais. Ela teve por objetivo proteger os Direitos Humanos e as liberdades fundamentais, permitindo um controle judiciário do respeito desses direitos individuais.

José Mauel Bandrés (1998, pp. 186-187), assim considera o valor deste documento internacional para a garantia de acesso à justiça:

O artigo $8^{\circ}$ da Declaração Universal de Direitos Humanos, ao proclamar o direito de toda pessoa a um recurso efetivo ante os tribunais nacionais competentes, que a ampare contra atos que violem seus direitos fundamentais reconhecidos pela Constituição ou pela Lei, institui as garantias jurídicas procedimentais necessárias e imprescindíveis para salvaguardar no Direito interno os direitos humanos e as liberdades públicas.

O Direito a um recurso efetivo não se reconhece na Declaração Universal dos Direitos Humanos como um ius nudum, ao servir esta cláusula como contenção dos espaços de imunidade dos poderes públicos, ao permitir submeter qualquer ato lesivo dos direitos e liberdades dos cidadãos à fiscalização de um tribunal de Direitos.

Inscreve-se este preceito, junto ao artigo 10 que consagra o direito à justiça, entre os pilares que sustentam a arquitetura jurídica da Declaração Universal dos Direitos Humanos, já que, como se adverte entre fundamentos ideológicos da Declaração, esta não busca, não se limita a proclamar formalmente os direitos e liberdades como uma mera aspiração dos homens e povos livres, todavia se interessa pela garantia real e eficaz desses direitos e liberdades, cuja proteção somente se pode assegurar em um Estado de Direito.

$\mathrm{O}$ artigo $8^{\circ}$ da DUDH tem tido o mérito de servir como direito humano de referência, que é objeto de recepção, em relações familiares, em 
pactos internacionais de direitos humanos de alcance universal, regional ou setorial.

A Convenção Europeia de Direitos Humanos dispõe em seu artigo $6^{\circ}$, inciso I, que todo indivíduo tem o direito à prestação jurisdicional em prazo razoável (CAPPELLETTI e GARTH, 1988), sendo que a Corte Europeia de Direitos Humanos chegou a condenar os Estados signatários a indenizar os lesados pela demora excessiva na prestação da justiça. O texto in verbis do artigo $6^{\circ}$, inciso I, assim dispõe:

Qualquer pessoa tem direito a que a sua causa seja examinada, equitativa e publicamente, num prazo razoável por um tribunal independente e imparcial, estabelecido pela lei, o qual decidirá, quer sobre a determinação dos seus direitos e obrigações de carácter civil, quer sobre o fundamento de qualquer acusação em matéria penal dirigida contra ela. O julgamento deve ser público, mas o acesso à sala de audiências pode ser proibido à imprensa ou ao público durante a totalidade ou parte do processo, quando a bem da moralidade, da ordem pública ou da segurança nacional numa sociedade democrática, quando os interesses de menores ou a protecção da vida privada das partes no processo o exigirem, ou, na medida em que julgada estritamente necessária pelo tribunal, quando, em circunstâncias especiais, a publicidade pudesse ser prejudicial para os interesses da justiça ${ }^{499}$.

Outro documento de grande relevância decorre da Convenção Americana de Direitos Humanos, conhecida por Pacto de São José da Costa Rica (1969), que em seu artigo $8^{\circ}$, inciso I, in verbis preceitua:

Toda pessoa terá o direito de ser ouvida, com as devidas garantias e dentro de um prazo razoável, por um juiz ou Tribunal competente, independente e imparcial, estabelecido anteriormente por lei, na apuração de qualquer acusação penal formulada contra ela, ou na determinação de seus direitos e obrigações de caráter civil, trabalhista, fiscal ou de qualquer outra natureza. (MAZZUOLI, 2008, p. 958).

A Convenção dispõe, portanto, que todo invidívudo tem direito fundamental à prestação jurisdicional sem dilações indevidas. O Brasil, na qualidade de signatário desta Convenção, ratificou-a em 1992 através do Decreto $n^{\circ} 678$.

499 Disponível em: http://reservadejustica.wordpress.com/2009/06/08/convencao-europeia-dedireitos-humanos-e-protocolos-adicionais/. Acessado em: 30.07.2012. 
É ainda a Convenção Americana sobre os Direitos Humanos, que em seu artigo 25 dispõe:

Art. 25. Toda pessoa tem direito a um recurso simples e rápido ou a qualquer outro recurso efetivo, perante os juízes ou tribunais competentes, que a proteja contra atos que violem seus direitos fundamentais reconhecidos pela Constituição, pela lei ou pela presente Convenção, mesmo quando tal violação seja cometida por pessoas que estejam atuando no exercício de suas funções oficiais ${ }^{500}$.

Há uma preocupação crescente no Direito Internacional no que tange à garantia do acesso à justiça por parte dos cidadãos, e de que este acesso seja eficaz, célere na realização de seu desiderato.

\section{Acesso à justiça como direito fundamental na Constituição Brasileira}

A Constituição da República Federativa do Brasil tem insculpido em seu artigo $5^{\circ}$, inciso XXXV que "a lei não excluirá da apreciação do Poder Judiciário lesão ou ameaça a direito". Assim, cada cidadão é parte legítima para acessar o Poder Judiciário requerendo a sua tutela em face de qualquer lesão ou ameaça de direito. Entretanto, tal garantia constitucional não versava em nenhum momento sobre o tempo processual, ou seja, o tempo de duração da lide. Neste caso, em se tratando de uma grande empresa em face de um cidadão comum, na medida em que esse ingressasse com ação contra aquela, a demora do processo traria certamente um maior ônus para o cidadão comum, uma vez que não disporia, em regra, dos recursos financeiros da empresa.

No Brasil, entretanto, foi somente a partir de 2004, por força da Emenda Constitucional 45, de 8 de dezembro de 2004 que foi inserido como direito fundamental constitucional, a garantia a razoável duração do processo. A referida emenda deu origem ao inciso LXXVIII do artigo $5^{\circ}$ da Constituição Federal com a seguinte redação: LXXVIII - a todos, no âmbito judicial e administrativo, são assegurados a razoável duração do processo e os meios que garantam a celeridade de sua tramitação.

Com este dispositivo constitucional, passa o Estado a ser responsável por atuar no sentido de tornar a tramitação dos processos mais célere, assegurando, destarte, uma razoável duração dos mesmos, de sorte que os menos favorecidos economicamente venham a experimentar uma factível distribuição de justiça.

$\overline{{ }_{500} \text { Disponível em: }}$ http://reservadejustica.wordpress.com/2009/06/08/convencao-europeia-de-direitos-humanos-e-protocolos-adicionais/. Acessado em: 30.07.2012. 
O que a Constituição Federal fez foi introduzir a efetividade e celeridade da tutela jurisdicional como direito fundamental. É neste sentido que o então Exm $^{\circ}$ Ministro do Supremo Tribunal Federal Carlos Alberto Menezes Direito preconizou:

O maior esforço que a ciência do direito pode oferecer para assegurar os direitos humanos é voltar-se, precipuamente, para a construção de meios necessários à sua realização nos Estados e, ainda, para o fortalecimento dos modos necessários de acesso à Justiça com vistas ao melhoramento e celeridade da prestação jurisdicional. (DIREITO, 1998, p. 142).

\section{Obstáculos Ao aCESso efetivo À Justiça}

\subsection{Obstáculo econômico}

Santos, apud Cappelletti e Garth considera os obstáculos de natureza econômica:

Quanto aos obstáculos econômicos, verificou-se que, nas sociedades capitalistas em geral, os custos da litigação eram muito elevados e que a relação entre o valor da causa e o custo da sua litigação aumentava à medida que baixava o valor da causa. Assim, na Alemanha, verificouse que a litigação de uma causa de valor médio na primeira instância de recurso custaria cerca de metade do valor da causa. Na Inglaterra verificou-se que em cerca de um terço das causas em que houve contestação os custos globais foram superiores aos do valor da causa. $\mathrm{Na}$ Itália, os custos da litigação podem atingir 8,4\% do valor da causa nas causas com valor elevado, enquanto nas causas com valor diminuto essa percentagem pode elevar-se a 170\% (Cappelleti e Garth, 1978, p.10 e ss.). Estes estudos revelam que a justiça civil é cara para os cidadãos em geral, mas revelam sobretudo que a justiça civil é proporcionalmente mais cara para os cidadãos economicamente mais débeis. É que são eles fundamentalmente os protagonistas e os interessados nas ações de menor valor e é nessas acções que a justiça é proporcionalmente mais cara, o que configura um fenômeno da dupla vitimização das classes populares face à administração da justiça (SANTOS, 1999, p. 168).

Os custos decorrentes do processo, envolvendo custas judiciais e honorários advocatícios constituem no Brasil um grande obstáculo ao acesso à Justiça. 
Os altos custos acabam sendo desanimadores para grande parte das pessoas que se veem envolvidas numa relação conflitiva que exige, para sua solução, uma prestação jurisdicional, principalmente quando a outra parte é detentora de grandes recursos financeiros e tem condições de prolongar a demanda, valendo-se de todas as possibilidades recursivas, o que deixa a parte pobre da relação jurídica em condição desvantajosa para ingressar com ação contenciosa.

O quadro abaixo, de dados extraídos do IBGE. (Instituto Brasileiro de Geografia e Estatística) nos dá uma idéia das condições econômicas dos brasileiros e nos permite perceber que, não obstante a garantia constitucional de que "o Estado prestará assistência jurídica integral e gratuita aos que comprovarem insuficiência de recursos" (artigo 5, LXXIV da Constituição Federal), as parcas condições econômicas pesam negativamente contra os despossuídos, uma vez que quem tem melhores condições financeiras tem mais possibilidades de vencer a demanda judicial ou procrastinar o resultado do processo através de inúmeros procedimentos e recursos aos tribunais superiores.

Tabela 4.2 - Arranjos familiares residentes em domicílios particulares, total e respectiva distribuição percentual, por classes de rendimento mensal familiar per capita, segundo as Grandes Regiões do Brasil - $2009^{501}$.

\begin{tabular}{|c|c|c|c|c|c||}
\hline \multirow{2}{*}{$\begin{array}{c}\text { Grandes } \\
\text { Regiões }\end{array}$} & \multicolumn{5}{|c||}{ Arranjos familiares residentes em domicílios particulares } \\
\cline { 2 - 6 } & $\begin{array}{c}\text { Total } \\
\end{array}$ & $\begin{array}{c}\text { Distribuição percentual, por classes de rendimento } \\
\text { mensal familiar per capita (salário mínio) (\%) }\end{array}$ \\
\cline { 2 - 6 } & arranjos & Até $1 / 4$ & $\begin{array}{c}\text { Mais de } 1 / 4 \\
\text { até } 1 / 2\end{array}$ & $\begin{array}{c}\text { Mais de } 1 / 2 \\
\text { até } 1\end{array}$ & Mais de 1 a 2 \\
\hline Brasil & 62.307 & 7.7 & 15.2 & 27.6 & 24.8 \\
\hline Norte & 4.586 & 11.6 & 22.0 & 30.3 & 18.8 \\
\hline Nordeste & 16.625 & 17.4 & 24.2 & 29.5 & 15.0 \\
\hline Sudeste & 27.020 & 3.4 & 10.5 & 26.4 & 29.0 \\
\hline Sul & 9.462 & 2.9 & 9.7 & 25.6 & 32.3 \\
\hline Centro-Oeste & 4.615 & 4.4 & 13.9 & 29.7 & 25.9 \\
\hline \hline
\end{tabular}

\footnotetext{
${ }^{501} \mathrm{http} / /$ www.ibge.gov.br/home/estatistica/populacao/condicaodevida/indicadoresminimos/sinteseindicsociais2010/SIS_2010.pdf. Acessado em: 23.08.2012.
} 
Se considerarmos que o salário mínimo no Brasil é em 2012 R \$622,00 (seiscentos e vinte e dois reais), fica evidente a condição de pobreza de grande parte dos trabalhadores brasileiros.

Pelos dados apresentados no quadro acima podemos constatar que um elevado número de famílias brasileiras vivem com renda inferior a 2 (dois) salários mínimos.

Estes dados nos levam a concluir que uma imensa parcela da população brasileira não tem condições de arcar com as custas judiciais e honorários advocatícios em um processo judicial.

Enquanto este obstáculo não for superado, as pessoas carentes de recursos financeiros continuarão a ter dificuldade quanto ao acesso à justiça, não obstante o instituto da Justiça Gratuita para os despossuídos.

\subsection{Obstáculo temporal e estrutural}

A lentidão dos processos constitui-se em outro fator de agravamento para os cidadãos com menos recursos, convertendo-se a morosidade do processo em um custo adicional. SANTOS (1999, p. 169), faz uma análise da morosidade do processo em alguns países europeus:

No final da década de 60, a duração média de um processo civil na Itália era, para o percurso das três instâncias, 6 anos e 5 meses (Resta, 1977, p.80); alguns anos mais tarde, na Espanha, essa duração era cerca de 5 anos e 3 meses (Cappelletti e Garth, 1978, p.14). No final da década de 60, as acções civis perante o tribunal de grande instância em França duravam 1,9 anos e perante o tribunal de primeira instância na Bélgica 2,3 anos (Cappelleti \& Garth, 1978). A análise de duração média dos processos civis e a consequente verificação do aumento da lentidão da justiça é um dos temas mais intrigantes da investigação sociológica sobre os tribunais nos nossos dias. Por um lado, verifica-se que a litigação civil tem vindo a diminuir de volume nas últimas décadas. Os estudos feitos na Itália neste campo (Resta, 1977, pp. 83 e ss.) corroboram inteiramente os produzidos em Espanha, onde Juan Toharia (1974, p.190) conclui que ao maior desenvolvimento social e econômico, e ao consequente aumento da vida jurídica civil e da conflitualidade social nesta área, tem correspondido um descréscimo das causas civis nos tribunais de justiça.

Não obstante as considerações acima levadas a efeito por Souza, ele em seguida constata que, mesmo ocorrendo a redução do número de litígios, não houve redução de tempo para a sua solução, antes houve um aumento constante 
da duração média dos processos civis. Santos (1999, p. 169) constata ainda que o mais intrigante "é o fato de este aumento se revelar resistente, não só às inovações parciais que o procuram controlar, mas também em relação às reestruturações globais do processo tendentes a eliminar por completo a lentidão da justiça". Tais constatações levam Santos (1999, p. 169) à seguinte conclusão:

Estas verificações têm levado a sociologia judiciária a concluir que as reformas do processo, embora importantes para fazer baixar os custos econômicos decorrentes da lentidão da justiça, não são de modo nenhum uma panacéia. É preciso tomar em conta e submeter a análise sistemática outros factores quiçá mais importantes. Por um lado, a organização judiciária e a racionalidade ou irracionalidade dos critérios de distribuição territorial dos magistrados. Por outro, a distribuição dos custos mas também dos benefícios decorrentes da lentidão da justiça. Neste domínio, e a título de exemplo, é importante investigar em que medida largos estratos da advocacia organizam e rentabilizam a sua actividade com base na demora dos processos e não apesar dela (Ferrari, 1983, 339: Resta, 1977, 87).

A burocracia do Poder Judiciário no Brasil está longe de atingir as condições necessárias para uma célere distribuição de justiça, é o que se depreende dos dados estatísticos do Poder Judiciário informados pelo Supremo Tribunal Federal referentes ao ano de $2000^{502}$. A média nacional, no ano de 2000, é de 01 (um) juiz para cada 22.680 habitantes, enquanto na Alemanha, a média é de 01 (um) juiz para cada 3.000 habitantes. No Estado do Paraná esta média é de 01 (um) juiz para cada 20.426 habitantes. O Estado do Paraná possuía 459 juízes (em 2000) para uma população de 9.375 .592 habitantes. Desta forma, para termos os mesmos padrões médios da Alemanha, seriam necessários 3.125 juízes somente no Paraná.

Ocorre que no Brasil o número de juízes em âmbito nacional era de 7.231 (em 2000) para atender uma população de 163.998.652 habitantes, sendo que o ideal considerando a média na Alemanha deveria ser de 54.666 juízes.

No ano de 2.000 foram distribuídos 11.207.948 processos em primeira instância, 1.741.182 em Segunda instância e 244.911 nos Tribunais Superiores. O número de processos distribuídos em primeira instância em comparação com o número de habitantes do país (1999 - 163.998.652) corresponde ao percentual de 6,8 \%. Da mesma forma, se compararmos o número de processos distribuídos em primeira instância com a População Economicamente Ativa (PEA) em 1999 ( 69.558.975), este percentual passa para $16,1 \%$.

\footnotetext{
${ }^{502}$ Banco de dados do Poder Judiciário. Disponível em: http://www.stf.jus.br/portal/cms/verTexto. asp?servico-estatistica\&pagina=pesquisaRamoDireito2001. Acessado em: 24.07.2012.
} 
Da análise destes números pode-se observar que o efetivo acesso à Justiça é precário em razão de questões estruturais, o que somado à morosidade da outorga da prestação jurisdicional em decorrência da escassez de magistrados, além de outros fatores estruturais, dificulta enormemente um efetivo acesso à Justiça aos cidadãos.

Faz-se necessário, portanto, que ocorram mudanças estruturais no poder judiciário de forma a facilitar o acesso à justiça, tornar o processo mais célere, contribuindo, destarte, para a prestação efetiva da justiça.

Dados mais recentes foram publicados pelo Conselho Nacional de Justiça $^{503}$. Considerando para o nosso objetivo, tão somente a estrutura judiciária do Estado de São Paulo, que é o Estado com maior número de processos em relação aos demais tribunais do país, verificamos o seguinte quadro:

\begin{tabular}{|l|c|c|c|c|c|}
\hline \multicolumn{1}{|c|}{ Estrutura } & 2004 & 2005 & 2006 & 2007 & 2008 \\
\hline $\mathrm{N}^{\circ}$ Magistrados & $1.693,00$ & 2.016 & 2.154 & 2.363 & 2.291 \\
\hline $\begin{array}{l}\text { Magistrados por } \\
100.000 \text { habitantes }\end{array}$ & 4.3 & 5.0 & 5.2 & 5.9 & 5.6 \\
\hline $\begin{array}{l}\mathrm{N}^{\circ} \text { Magistrados de } \\
2^{\circ} \text { grau }\end{array}$ & 132 & 360 & 360 & 360 & 360 \\
\hline Casos novos 2 $2^{\circ}$ grau & 119.568 & 422.781 & 496.908 & 490.294 & 548.129 \\
\hline $\begin{array}{l}\text { Casos pendentes } \\
\text { de julgamento em } \\
2^{\circ} \text { grau }\end{array}$ & 267.701 & 505.352 & 553.771 & 581.808 & 580.430 \\
\hline $\begin{array}{l}N^{\circ} \text { decisões que } \\
\text { põem fim ao proces- } \\
\text { so 2 } 2^{\circ} \text { grau }\end{array}$ & 93.620 & 374.362 & 467.662 & 492.881 & 553.771 \\
\hline $\begin{array}{l}\text { Taxa de congestio- } \\
\text { namento no 2 } 2^{\circ} \text { grau }\end{array}$ & $75,8 \%$ & $59,7 \%$ & $55,5 \%$ & $54,0 \%$ & $50.9 \%$ \\
\hline $\begin{array}{l}\text { Taxa de congestio- } \\
\text { namento de } 1^{\circ} \text { grau }\end{array}$ & $79,5 \%$ & $81,3 \%$ & $82,0 \%$ & $84,3 \%$ & $84,0 \%$ \\
\hline $\begin{array}{l}\text { Assistência Judici- } \\
\text { ária Gratuita } \text { No de }^{\circ} \\
\text { Pessoas atendidas }\end{array}$ & Indisponível & 5.470 .401 & 5.434 .866 & 6.968 .511 & 8.158 .065 \\
\hline
\end{tabular}

Do quadro acima, destacando-se os dados gerais de magistrados no Estado de São Paulo, depois o número de magistrados de $2^{\circ}$ grau, casos novos, casos pendentes, casos julgados, percentual de congestionamento dos processos, e em seguida a taxa de congestionamento de processos em primeira instância, observa-se que o número de processos e decisões é bem menor que o número de novos processos que se iniciam a cada ano, o que gera um congestionamento enorme de processos, e que vai aumentando a cada ano. O número de casos pendentes de 2004 para 2008 mais que dobraram. O número de magistrados para cada 100.000 habitantes é pequeno.

${ }^{503}$ Disponível em: http://www.cnj.jus.br/images/conteudo2008/pesquisasjudiciais/tjsp.pdf. Acessado em: 25.07.2012. 
Os obstáculos temporais associados aos estruturais têm ocasionado morosidade nos processos e congestionamento de processos nos tribunais, o que tem resultado em grande prejuízo para todos quantos precisam de uma Justiça célere.

\subsection{Obstáculo de natureza pessoal}

Cappelletti e Garth (1988) ao fazer menção do obstáculo de natureza pessoal utilizam-se da expressão "possibilidade das partes" para se referir ao fato de que algumas espécies de litigantes gozam de uma gama de vantagens estratégicas, como organizações ou pessoas com muitos recursos financeiros, que acabam tendo vantagens em um litígio judicial, uma vez que podem pagar para litigar e também suportar as delongas do litígio; a "aptidão para reconhecer um direito e propor uma ação ou sua defesa", o que exige que a pessoa tenha uma boa educação formal e, por conseguinte, melhores condições para reconhecer seus direitos e se valer do aparato judicial para reivindicá-lo.

\section{Caminhos de EFETIVAÇÃo do ACESSo À JustiÇa.}

O estudo concernente ao problema do acesso à justiça levou Cappelletti e Garth (1988, pp. 31-73) a se utilizarem de uma metáfora oriunda de um fenômeno da física - ondas -, para se referir às várias formas pelas quais o acesso à justiça ocorreu historicamente, mormente nos países ocidentais, no afã de proporcionar maior efetividade no acesso à justiça. Assim, consideram os referidos autores três ondas de acesso à justiça (CAPPELLETTI e GARTH, 1998, pp. 31-73).

A primeira onda ${ }^{504}$ (consistiu na instituição da assistência judiciária, quando os ordenamentos jurídicos então vigentes procuraram assegurar a prestação jurídica gratuita às pessoas pobres, desprovidas de recursos financeiros para promover uma ação ou para se defender em uma ação judicial.

A segunda onda consistiu nos esforços do Estado para proporcionar a representação dos interesses difusos, o que exigiu uma mudança de mentalidade por parte dos operadores do direito, tendo em vista que antes do advento dos direitos coletivos a relação processual era de natureza privatista, exigindo a ocorrência de uma lesão direta e pessoal. O mesmo se aplica no que se refere à coisa julgada, tendo em vista que seus efeitos sempre tiveram de quedar-se restritos às partes litigantes da relação jurídico-processual, passando doravante a beneficiar todos os cidadãos afetados pelo objeto da ação, mesmo que não

\footnotetext{
${ }^{504}$ CAPPELLETTI, Mauro, GARTH, Bryant. Acesso à Justiça, Porto Alegre: Sérgio Antônio Fabris Editor, 1988, p. $31 \mathrm{~s}$.
} 
tenham sido diretamente parte no processo, além de outros, como por exemplo a citação e os poderes do juiz.

A terceira onda, mais recente, consiste num alargamento da visão do acesso à justiça em comparação às duas ondas que a precederam, uma vez que aquelas se ocuparam em enfocar os problemas pertinentes ao acesso ao Poder Judiciário, enquanto este novo enfoque do acesso à justiça se volta para a efetividade dos direitos, apontando a necessidade de reforma dos procedimentos jurisdicionais.

\subsection{A tutela COletiva COMO instrumento de EFETIVAÇÃo do ACESSO À JUSTIÇA}

Cappelletti e Garth (1988, p. 26) consideram a questão que envolve os interesses difusos:

Interesses "difusos" são interesses fragmentados ou coletivos, tais como o direito ao ambiente saudável, ou à proteção do consumidor. O problema básico que eles apresentam - a razão de sua natureza difusa - é que, ou ninguém tem direito a corrigir a lesão a um interesse coletivo, ou o prêmio para qualquer indivíduo buscar essa correção é pequeno demais para induzi-lo a tentar uma ação.

Os interesses difusos, como por exemplo, os interesses envolvendo o meio ambiente, afetam várias pessoas ao mesmo tempo. Entretanto, o custo para apenas um indivíduo ingressar com uma ação é muito alto e, às vezes, até mesmo para um número maior de pessoas, o custo continua sendo alto, isto quando se consegue reuní-las para lutar pelos seus próprios direitos.

Atualmente, no Brasil, o Ministério Público tem sido bastante atuante na defesa dos cidadãos quando se trata de interesse difuso, uma vez que tem o Ministério Público legitimidade para propor a Ação Civil Pública, na qual são contemplados os direitos difusos.

A segunda onda foca sua atenção para a proteção dos interesses difusos. Ela teve início entre os anos 1965 e 1970 nos Estados Unidos da América (CAPELLETTI e GARTH, 1988, p. 49). Antes de seu advento nos Estados Unidos o processo era percebido como instrumento de resolução de conflitos entre duas partes, numa ótica totalmente individual, inexistindo espaço para a proteção dos interesses supraindividuais.

Ganharam espaço a partir de então os chamados litígios de Direito Público, em razão de sua vinculação com assuntos relevantes de política envolvendo grandes grupos de pessoas. Ocorreram então mudanças em 
determinados conceitos processuais, sobretudo no que tange à legitimidade ativa, ao permitir que cada vez mais indivíduos ou grupos passassem a atuar na esfera de interesses difusos, o que acabou por demandar uma nova postura do juiz em relação a conceitos processuais básicos como a citação e o direito de ser ouvido. A esse respeito consideram Cappelletti e Garth (1988, p. 50):

Uma vez que nem todos os titulares de um direito difuso podem comparecer a juízo - por exemplo, todos os interessados na manutenção da qualidade do ar, numa determinada região - é preciso que haja um "representante adequado" para agir em benefício da coletividade, mesmo que os membros dela não sejam "citados" individualmente. Da mesma forma, para ser efetiva, a decisão deve obrigar a todos os membros do grupo, ainda que nem todos tenham tido a oportunidade de ser ouvidos. Dessa maneira, outra noção tradicional, a da coisa julgada, precisa ser modificada, de modo a permitir a proteção judicial efetiva dos interesses difusos.

As modificações apontadas por Cappelletti e Garth na concepção de certos conceitos processuais deram lugar à mudança na prática processual. Mudança de grande relevância foi a que se refere à coisa julgada. Se antes a coisa julgada atingia tão somente as pessoas que participavam do processo como partes, agora, tornava-se possível que, em alguns casos, uma ação judicial vinculasse pessoas que não tivessem integrado um determinado litígio e dele sequer tivessem tomado conhecimento.

As mudanças levadas a efeito pela segunda onda do acesso à justiça possibilitaram o rompimento de uma visão individualista do processo e o surgimento de uma visão coletiva, social. É sob este foco que devem ser abordadas as ações coletivas que representam um considerável progresso no acesso de todos os cidadãos à justiça com o fito de resguardarem os interesses difusos e públicos.

A discussão em torno do acesso à justiça conduz necessariamente, na atualidade, à discussão sobre os direitos coletivos.

Ao discorrer sobre os direitos subjetivos públicos e liberdades públicas, como por exemplo, direito ao devido processo legal (art. $5^{\circ}$, LV C.F.), a uma administração pública proba e eficiente (art. 5, LXXIII e art. 37 da C.F), a um meio ambiente equilibrado (art. $5^{\circ}$, LXXIII e art. 225 da C.F.), a ser respeitado enquanto consumidor (art. 5\% XXXII e art. 170 da C.F.), pode incluir entre esses direitos o "direito de acesso à Justiça", também constante do artigo $5^{\circ}$, XXXV da Constituição Federal.

Acerca desses direitos observa Mancuso (1998, p. 29): 
Esses direitos subjetivos públicos e essas liberdades públicas, quando desrespeitados ou obstados, ensejam o acesso à Justiça, através dos instrumentos processuais de índole coletiva a que já aludimos: ação popular, ação civil pública, mandado de segurança coletivo, arguição de inconstitucionalidade, ações coletivas do Código de Defesa do Consumidor, mandado de injunção em modo coletivo. Sem embargo, outros desses direitos e liberdades, por sua natureza personalíssima, somente ensejam ações de natureza individual: a liberdade de locomoção, garantia de habeas corpus; o direito à informação, garantido pelo habeas data, a ofensa a direito individual, líquido e certo, pelo mandado de segurança.

Em nossos dias, o acesso à justiça desses direitos subjetivos públicos e liberdades públicas através de ações coletivas, está se constituindo na grande dificuldade a ser enfrentada pelo processo civil e pelo Poder Judiciário.

Não obstante Mancuso ter se referido a esta dificuldade enfrentada pelo processo civil e pelo Poder Judiciário em 1994, o que se observa é que muitos problemas ainda continuam existindo, o que levou à elaboração de um Anteprojeto de Código Brasileiro de Processos Coletivos que traz em artigo $2^{\circ}$ os "princípios da tutela jurisdicional coletiva", sendo o primeiro destes princípios o "acesso à justiça e à ordem jurídica justa”.

Grinover (2007, p. 12) fazendo alusão ao princípio do acesso à justiça discorre:

O tema do acesso à justiça, dos mais caros aos olhos dos processualistas contemporâneos, não indica apenas o direito de aceder aos tribunais, mas também o de alcançar, por meio de um processo cercado das garantias ao devido processo legal, a tutela efetiva dos direitos violados ou ameaçados. Na feliz expressão de Kazuo Watanabe, o acesso à justiça resulta no "acesso à ordem jurídica justa".

[...] Percebe-se, assim, que o acesso à justiça para a tutela de interesses transindividuais, visando à solução de conflitos que, por serem de massa, têm dimensão social e política, assume feição própria e peculiar no processo coletivo. O princípio que, no processo individual, diz respeito exclusivamente ao cidadão, objetivando nortear a solução de controvérsias limitadas ao círculo de interesses da pessoa, no processo 
coletivo transmuda-se em princípio de interesse de uma coletividade, formada por centenas, milhares e às vezes milhões de pessoas.

E o modo de ser do processo, que, quando individual, obedece a esquemas rígidos de legitimação, difere do modo de ser do processo coletivo, que abre os esquemas da legitimação, prevendo a titularidade da ação por parte do denominado "representante adequado", portador em juízo de interesses e direitos de grupos, categorias, classes de pessoas.

Vê-se que o tema do acesso à justiça está umbilicalmente ligado ao tema dos direitos coletivos e processo coletivo. $\mathrm{O}$ direito tem experimentado nas últimas décadas uma profunda mudança face à emergência dos direitos coletivos e à necessidade de instrumentos aptos a tutelá-los.

Os direitos coletivos, indicados pelos interesses difusos, coletivos e individuais homogêneos, abrem novas perspectivas de acesso à justiça por parte de grande número de pessoas. Agora, ao invés de ingressar solitariamente com uma ação, assumindo sozinho o risco da sucumbência e custas judiciais, o cidadão pode ingressar solidariamente com uma ação no sentido de defender interesses de uma coletividade.

A flexibilização proposta pelo Anteprojeto de Código de Processo Coletivo e pelo Projeto de Lei 5.139/2009 em vários de seus artigos objetivava tornar o processo coletivo menos rígido que o processo individual, e criar as condições de adequação a esta nova sistemática processual, de forma a torná-la mais efetiva face às demandas coletivas.

O Projeto de Lei 5.139/2009, não obstante tenha sido rejeitado pela Comissão de Constituição e Justiça do Congresso Nacional no mês de março de $2.010^{505}$, constituiu em um movimento do direito no sentido de buscar um instrumento eficaz de tutela dos direitos coletivos, e contribuiu para fomentar uma maior consciência jurídica face aos processos envolvendo direitos coletivos.

Almeida (2003, p. 68) aponta o acesso à justiça como um novo método de pensamento:

O direito processual deve ser concebido como instrumento de transformação da realidade social. É necessário hoje, portanto, o seu enfoque dentro do contexto social; só assim será possível alcançar a sua legitimidade instrumental com a observância dos valores principiológicos do Estado Democrático de Direito.

\footnotetext{
${ }^{505}$ Disponível em: http://www.camara.gov.br/sileg/Prop_Detalhe.asp?id=432485. Acessado em: 10.08.2012.
} 
Portanto, falar em acesso à justiça como novo método de pensamento pressupõe o rompimento com a neutralidade positivista, que impede a justiça de ser justiça, o direito de ser direito, a democracia de ser democracia. Impõe, assim, a concepção dinâmica, portanto aberta, do Direito, concepção essa que, transmudada para o direito processual, o torna um instrumento de realização de justiça por intermédio dos escopos jurisdicionais.

Nesse contexto, o acesso à justiça deve ser concebido como o mais fundamental dos direitos, como o mais básico dos princípios processuais e como uma garantia constitucional fundamental.

Importa, com efeito, em conceber o acesso à justiça em seu aspecto substancial, no sentido de ser o direito ao acesso a uma ordem jurídica realmente justa e não o direito à mera admissão em juízo.

$\mathrm{O}$ acesso à justiça nos termos concebidos por Almeida exige uma mudança de paradigma por parte dos operadores do direito, uma mudança na forma de conceber o processo, não como um fim, mas como um meio, como instrumento de realização de justiça, portanto, no seu aspecto substantivo, e não meramente formal.

\subsection{OS JUIZADOS ESPECIAIS COMO MEIOS CÉLERES DE ACESSO À JUSTIÇA}

A especialização para o tratamento de algumas modalidades de causas e processos é uma tendência atual. Cappelletti e Garth (1988, p. 90) consideram que "o movimento mais importante em relação à reforma do processo se caracteriza pelo que podemos denominar de desvio especializado e pela criação de tribunais especializados.

A sua criação no Brasil foi prevista pelo inciso I do artigo 98 da Constituição brasileira de 1988, sendo que sua efetiva implantação só veio a ocorrer após a aprovação da Lei Federal n. ${ }^{\circ}$ 9.099, de 26 de setembro de 1995. Até então, funcionava o antigo Juizado de Pequenas Causas que julgava e processava demandas cujos valores não poderiam ultrapassar 20 salários mínimos.

O Juizado Especial possibilita soluções em tempo menor, se comparado com o procedimento comum. Além disso, o processo é mais econômico, tanto para o cidadão quanto para o Judiciário.

Os juizados especiais cíveis e criminais têm contribuído significativamente para o acesso à justiça no Brasill. Muitas pessoas que antes se sentiam desencorajadas em buscar a justiça, agora o fazem em razão da celeridade e 
desburocratização do processo nos juizados especiais, nos quais a decisão final (sentença) ocorre com muito maior rapidez que nos processos ordinários da justiça comum.

\subsection{A Assistência Judiciária como instrumento de efeTivaÇão de ACESSO À JUSTIÇA Às PESSOAS DECLARADAMENTE POBRES.}

Criada pela Lei 1.060/50, a assistência judiciária tem sido desde então regulamentada, possibilitando que as pessoas destituídas de recursos financeiros tenham um advogado que atue em dedesa de seus direitos.

Já no Estado de São Paulo, como afirma Lara (2002, p. 82) a Assistência Judiciária surgiu em 1947, como serviço público estadual, a partir da edição do Decreto-lei $n^{\circ} 17.330$, que criou o Departamento Jurídico do Estado.

Discorrendo sobre o desenvolvimento da assistência judiciária considera Lara (2002, p. 84):

Assim, durante longos anos de experiência, mais de cinquenta na prestação de assistência judiciária, antecedendo até mesmo a Lei $\mathrm{n}^{\mathrm{o}}$ 1.060/50, o trabalho que inicialmente limitava-se a poucos advogados, com tímida atuação na Capital, cresceu e ganhou força em todo território do Estado, em todas as áreas do Direito, na Justiça Estadual e Federal, em todas as instâncias.

É louvável o trabalho que a Assistência Judiciária tem prestado ao longo dos anos, em todos os rincões do país, possibilitando às pessoas declaradamente pobres o acesso à justiça, acompanhado por um advogado que estará como seu patrono da causa, defendendo os seus interesses.

\subsection{A Defensoria Pública como instrumento de efetivação de acesso À JUSTIÇA AOS NECESSITADOS}

A Constituição Federal prevê em seu art. 134 a instituição da Defensoria Pública como "instituição essencial à função jurisdicional do Estado, incumbindo-lhe a orientação jurídica e a defesa, em todos os graus, dos necessitados, na forma do artigo $5^{\circ}$, LXXIV".

A Defensoria Pública se constitui de um corpo autônomo de funcionários públicos, com o objetivo de oferecer defensor aos necessitados que vão a juízo. A Lei Complementar $n^{\circ} 80$, de 1994, ofereceu as normas gerais a que se refere o parágrafo único do art. 134 da Constituição Federal. Temos, como exemplo, algumas funções institucionais da Defensoria Pública previstas na lei 
complementar sob exame: promover, extrajudicialmente, a conciliação entre as partes em conflito de interesses; patrocinar ação penal privada e a subsidiária da pública; patrocinar ação civil; patrocinar defesa em ação penal; patrocinar defesa em ação civil e recorrer; atuar como Curador Especial nos casos previstos em lei; exercer a defesa da criança e do adolescente.

A Defensoria Pública é parte legítima para propor as ações coletivas, nos termos do Código de Defesa do Consumidor e da Lei da Ação Civil Pública.

\subsection{As FACULdAdes de diREito E A PRESTAÇÃo JUdiCiÁRia: SEU PAPEL NA EFETIVAÇÃO DO ACESSO À JUSTIÇA.}

O insigne professor José Afonso da Silva falando sobre a cidadania e o seu exercício considera:

[...] é o reflexo dos direitos fundamentais da pessoa humana, que têm merecido pouca atenção no ensino jurídico, para não dizer que não têm desmerecido qualquer atuação, e sem a plena consciência da titularidade desses direitos ninguém será efetivo partícipe da cidadania. Mas as Faculdades de Direito podem e devem exercer um papel importante no preparo da cidadania não apenas pela oferta do ensino regular. Pode fazê-lo, também, pela prestação de serviços à comunidade. (SILVA, 2000, p. 10).

As faculdades de direito em muito tem contribuído para ampliar o acesso à justiça a todos. Regulamentadas por Decreto Federal, as faculdades de direito, regularmente constituídas, precisam oferecer formação prática para os alunos. Neste sentido, o Núcleo de Prática Jurídica, com seus escritórios experimentais, com a participação de advogados contratados pela faculdade, e com a participação de alunos estagiários, atua no sentido de prestar assistência jurídica à comunidade de baixa renda.

Muitos processos são iniciados e concluídos pelos escritórios presentes nas faculdades, mormente na esfera civil e criminal, trazendo grande benefício para a população.

Tal tem ocorrido nas cidades brasileiras em que há faculdades de Direito em condições de prestar tal serviço.

\subsection{A CONCILIAÇÃo COMO MEIO dE RESOluÇÃo de CONFLITOS E SUA IMPORTÂNCIA PARA A EFETIVAÇÃO DO ACESSO À JUSTIÇA}

Outra forma de resolução de conflitos que está em crescimento no Brasil é a conciliação. 
Há que se diferenciar a conciliação judicial da conciliação extrajudicial.

Grinover (2007, p. 12) observa que "a conciliação vem prevista no CPC e, como princípio, desde a Constituição do Império de 1824 - art. 161: 'em se fazer constar que se tem intentado o meio da reconciliação, não se começará processo algum'. Aqui o germe da conciliação pré-processual, por ocorrer antes de instaurado o processo".

O CPC em seu artigo 331 institui a obrigatoriedade da audiência judicial de conciliação antes de se passar à fase instrutória do processo. A conciliação é possível a qualquer momento durante o processo, desde que antes da sentença.

Grinover (2007, p. 12) pontua o caráter totalmente necessário da conciliação: "O que devemos encarar, sem medo ou preconceito, é o fato de que o Poder Judiciário, ao menos no Estado de São Paulo, não mais está capacitado para atender à demanda: se antes temia-se a litigiosidade contida, teme-se hoje ante a litigiosidade expandida".

Tal modalidade tem sido incentivada pelo Conselho Nacional de Justiça, que lançou pela primeira vez no ano de 2006 a campanha intitulada "Conciliação Já!'”506. Esta campanha instituiu a semana nacional de conciliação, que ocorre todo ano.

Mais recentemente no Brasil, em alguns Estados da Federação, o Tribunal de Justiça firmou convênio com algumas Faculdades de Direito, sendo que pessoas que recorrem ao Poder Judiciário são encaminhadas às Faculdades, que tem um espaço físico específico, com salas de audiência próprias para o atendimento destas pessoas. Ali, alunos de direito, acompanhados por professores atendem a parte interessada, tomam conhecimento de sua necessidade, da possibilidade jurídica do que por ela está sendo pleiteado, e convida a parte adversa para que compareça num determinado dia e hora, para participar de uma audiência de conciliação. Esta audiência é realizada por pessoa credenciada junto ao Tribunal de Justiça (professores formados em direito) que atende os que procuram o setor de conciliação acompanhados por alunos, quando então, tenta-se a conciliação, que sendo frutífera é tomada a termo, com a assinatura das partes, e encaminhada para homologação junto ao Poder Judiciário, sendo que a homologação tem força de sentença judicial.

Vemos assim, um sistema de certa forma híbrido, uma vez que algumas audiências de conciliação ocorrem no espaço fora do tribunal, como p. ex. no espaço de uma faculdade de direito, todavia, tais acordos são posteriormente homologados pelo tribunal, sem que as partes tenham comparecido ao tribunal, à presença de um juiz estatal.

A conciliação extrajudicial, todavia, consiste numa forma de resolução de conflitos onde todo o processo ocorre fora do tribunal, e caracteriza-se

\footnotetext{
${ }^{506}$ Disponível em: http://www.cnj.jus.br/index.php?option=com_content\&view=article\&id=9282 \&Itemid=675. Acessado em: 28.07.2012.
} 
por ser um método de autocomposição, uma vez que as partes chegam a um acordo entre si, sem a imposição de um terceiro, como ocorre na arbitragem (heterocomposição).

Além do que, a conciliação põe fim ao conflito e não fim a um processo, sendo, portanto, mais eficaz no que tange à pacificação social, podendo o acordo firmado ser levado à homologação pelo Poder Judiciário, caso necessário, ou tão somente através de instrumento público.

A conciliação tem sido importante instrumento na resolução de conflitos, e tem obtido grande sucesso nas conciliações judiciais realizadas nos tribunais e fora dos tribunais através de convênios firmados entre os tribunais e as faculdades de direito, e de igual forma através de convênios firmados entre a Defensoria Pública e as faculdades de direito.

É certo que a conciliação exige uma mudança de mentalidade dos operadores do direito, tendo em vista que sua prática requer a presença de um conciliador apto a negociar, que domine as técnicas de negociação, que saiba ouvir as partes, que seja ponderado em suas colocações, que tenha habilidade relacional, dentre outras qualidades.

\section{Conclusão}

Podemos concluir que no Brasil tem-se experimentado mudanças significativas com vistas a viabilizar um maior acesso à justiça. As ações coletivas, mormente no caso dos direitos difusos, onde toda uma coletividade é beneficiada com a sentença, a instituição dos juizados especiais, a assistência judiciária gratuita prestada diretamente pela Defensoria Pública, ou em razão do convênio firmado entre a Procuradoria Geral do Estado e a Ordem dos Advogados do Brasil, bem como dos convênios firmados entre a Defensoria Pública e as universidades ou faculdades com cursos de direito, o convênio firmado entre os Tribunais de Justiça e faculdades de direito, encaminhando às faculdades de direitos casos que chegam ao Tribunal para que procedam à conciliação, que uma vez restando frutífera é homologada pelo Tribunal. Enfim, são várias as modalidades de busca de soluções para os conflitos que chegam aos tribunais pelos caminhos que se afigurem mais céleres e econômicos.

Entretanto, muito há a ser superado, pois os problemas de natureza econômica, a morosidade dos processos, dentre outros, ainda continuam sendo óbices à realização efetiva da justiça.

Há a necessidade de, além de novos caminhos para a solução dos conflitos, que os tribunais atuem com mais celeridade, que se aumente o número de juízes, e as regras processuais sejam flexibilizadas de forma a possibilitar uma maior agilidade no andamento do processo e uma sentença em tempo mais reduzido. 
É neste quadro que merece destaque os processos coletivos, voltados para a tutela dos interesses difusos, coletivos e individuais homogêneos.

Faz-se necessário nos processos coletivos uma maior flexibilização das regras processuais, com vista a possibilitar uma maior celeridade no processo. Além do que, os processos coletivos podem contribuir para a redução de muitos processos individuais, pelo fenômeno da continência, conexão e litispendência, possibilitando que vários processos que tratem da mesma matéria, ainda que com autores diversos, sejam reunidos num só processo. Enfim, os processos coletivos tendem a reduzir o número de processos individuais, além do que, podem contribuir para a realização de uma justiça que seja de fato efetiva na solução de problemas que envolvam grande número de sujeitos.

$\mathrm{O}$ advento do processo coletivo exige do legislador e dos tribunais uma melhor adequação legislativa e procedimental, além de uma mudança de mentalidade jurídica, uma superação dos conceitos estratificados do processo individual, e a assimilação de conceitos próprios do direito social.

Merecem destaque de igual forma as vias extrajudiciais de resolução de conflitos, que tem crescido no Brasil e que muito podem contribuir para a prestação de uma justiça mais célere, desburocratizada e humana, como é o caso da arbitragem, da conciliação e da mediação, ainda que tais institutos não sejam o objeto do presente trabalho.

A ampliação do acesso à justiça exige tanto uma ação por parte do Estado, de forma a criar as condições para a prestação de uma justiça mais célere e desburocratizada, haja vista que a morosidade processual é um dos maiores entraves do Judiciário no Brasil, quanto uma mudança de mentalidade por parte dos operadores do direito e das pessoas em geral, de sorte que novas possibilidades processuais e procedimentais sejam buscadas com vistas a uma efetivação crescente do acesso à justiça, garantindo destarte a realização de forma concreta deste direito fundamental. 


\section{REFERÊNCIAS}

ALMEIDA, Gregório Assagra. Direito Processual Coletivo Brasileito: um novo ramo do direito processual. São Paulo: Saraiva, 2003.

BANDRÉS, José Manoel. La Declaración Universal de Los Derechos Humanos. Comentário artículo por artículo. (Coord.) Xavier Pons Rafols, Associación para lãs Naciones Unidas em Espana. Barcelona: Icaria Editorial, 1998.

BOBBIO, Norberto. A Era dos Direitos. 10. ed., Rio de Janeiro: Campus, 1992.

CAPPELlETTI, Mauro e GARTH, Bryant. Acesso à Justiça. Porto Alegre: Sérgio Antônio Fabris Editor, 1988.

CARDOSO, Fernando Henrique. Capitalismo e Escravidão no Brasil Meridional. 2. ed. Rio de Janeiro: Paz e Terra, 1977.

DIREITO, Carlos Alberto Menezes. A prestação jurisdicional e a efetividade dos direitos declarados. Revista da EMERJ, vol. 1., 1998.

FISCHER, Roger; URY, William; Bruce Patton. A negociação de acordos sem concessões. Rio de Janeiro: Imago, 1994.

FRANCO, Maria Sylvia de carvalho. Homens Livres na Ordem Escravocrata. 4. ed., São Paulo: Unesp, 1997.

GRINOVER, Ada Pellegrini in. GRINOVER, Ada Pellegrini, MENDES, Aluisio Gonçalves de Castro e WATANABE, Kazuo. Direito Processual Coletivo e o anteprojeto de Código Brasileiro de Processos Coletivos. São Paulo: Revista dos Tribunais, 2007.

GRINOVER, Ada Pellegrini; WATANABE, Kazuo e LAGRASTA NETO, Caetano (Coord.). Mediação e Gerenciamento do Processo. In Revolução na Prestação Jurisdicional. São Paulo: Atlas, 2007.

KOMPARATO, Fábio Konder. A Afirmação Histórica dos Direitos Humanos. 4. ed., São Paulo: Saraiva, 2005.

LARA, Rubens. Acesso à Justiça. O Princípio Constitucional e a Contribuição Prestada pelas Faculdades de Direito. São Paulo: Método, 2002. 
MANCUSO, Rodolfo de Camargo. Ação Popular. 3. ed., São Paulo: Revista dos Tribnais, 1998.

MAZZUOLI, Valerio de Oliveira (Org.). Coletânea de direito internacional e Constituição Federal, 6. ed., São Paulo: RT, 2008.

MESQUiTA, Miguel (Org). Código de Processo Civil Português. 23. ed., Coimbra: Almedina, 2009.

NABUCO, Joaquim. O Abolicionismo. 5. ed. Rio Janeiro: Vozes, 1988.

SANTOS, Boaventura de Sousa. Pela Mão de Alice. O social e o político na pós-modernidade. Porto Alegre: Sérgio Antônio Fabrir Editor, 1998.

SILVA, José Afonso da. Faculdades de Direito e Construção da Cidadania. In Revista do Advogado. São Paulo: AASP, n. 59, junho/2000. 